\title{
Editorial: Understanding and Communicating Wildland Fire Smoke Risk
}

\author{
Gayle S. W. Hagler ${ }^{1}$, Sarah B. Henderson ${ }^{2}$, Sarah McCaffrey ${ }^{3}$, Fay H. Johnston ${ }^{4,5}$, \\ Susan Stone ${ }^{6}$, Ana Rappold ${ }^{1}$ and Wayne E. Cascio ${ }^{1 *}$ \\ ${ }^{1}$ United States Environmental Protection Agency, Office of Research and Development, Research Triangle Park, NC, \\ United States, ${ }^{2}$ Environmental Health Services, British Columbia Centre for Disease Control (BCCDC), Vancouver, BC, \\ Canada, ${ }^{3}$ Rocky Mountain Research Station, United States Forest Service, Fort Collins, CO, United States, ${ }^{4}$ Environmental \\ Health Group, Menzies Institute for Medical Research, University of Tasmania, Hobart, TAS, Australia, ${ }^{5}$ Public Health \\ Services, Department of Health, Tasmanian Government, Hobart, TAS, Australia, ${ }^{6}$ United States Environmental Protection \\ Agency, Office of Air Quality Planning and Standards, Research Triangle Park, NC, United States
}

Keywords: wildland fire, air pollution, smoke, wildfire, PM2.5, risk communication

\section{Editorial on the Research Topic}

\section{Understanding and Communicating Wildland Fire Smoke Risk}

Globally, smoke from landscape fires-including wildland fire (encompassing wildfires and prescribed fires), agricultural burning, tropical deforestation fires, peat fires, and grass fires-is estimated to cause 339,000 deaths annually (1). Epidemiological, clinical, animal, and cellular studies support a positive association between short-term exposure to wildland fire smoke and premature death and respiratory disease, namely exacerbation of asthma, bronchitis, and pneumonia (2-4). Emerging data suggest that exposure to wildland fire smoke also increases the

\section{OPEN ACCESS}

Edited and reviewed by:

Mohiuddin Md. Taimur Khan,

Washington State University Tri-Cities,

United States

*Correspondence:

Wayne E. Cascio

Cascio.Wayne@epa.gov

Specialty section:

This article was submitted to Environmental health and Exposome,

a section of the journal

Frontiers in Public Health

Received: 07 June 2021

Accepted: 20 August 2021

Published: 29 September 2021

Citation:

Hagler GSW, Henderson SB, McCaffrey S, Johnston FH, Stone S,

Rappold A and Cascio WE (2021)

Editorial: Understanding and Communicating Wildland Fire Smoke Risk. Front. Public Health 9:721823. doi: 10.3389/fpubh.2021.721823 risk of clinical cardiovascular events, such as myocardial infarction, heart rhythm disturbances, stroke, out-of-hospital cardiac arrest, and acute heart failure $(3,5,6)$. In addition, the potential for exposure to wildfire smoke during pregnancy to affect birth weight and prematurity is under exploration $[(4,7,8)$ and references therein].

Quantifying the economic costs of wildfire smoke exposure, in the United States (US), the direct burden has been estimated to be more than \$11 billion US dollars per year for short-term exposures and more than $\$ 76$ billion per year for long-term exposures (9). Similar impacts have been estimated in Canada (10) and Australia (11). The indirect economic burden is likely much higher.

Wildfire smoke exposure risk is expected to increase in the future (12). Abatzoglou and Williams (13) determined that anthropogenic climate change and its effects on fuel aridity contributed to nearly a doubling of forest fire area in the western US over 1984-2015. On a global scale, scientists predict that climate change will result in "longer, hotter, and drier fire seasons" that increase the risk of severe wildfires and associated health impacts, including those from smoke exposure (14).

Given the increasing public health threat of wildland fire smoke, environmental health scientists are challenged to define at-risk populations and provide data and tools to support health protective information and decisions. Public health and healthcare professionals rely on these scientific advances to communicate about risk and risk reduction strategies. Predicting wildland fire smoke exposure is critical to risk reduction, and this must occur in concert with communication about health protective resources. For example, the severe acute respiratory syndrome coronavirus 2 (SARS-CoV-2) pandemic was a critical co-occurring public health risk during the 2020 and 2021 wildfire seasons (15, 16). Considering wildfire smoke and SARS-CoV-2 together, specialized guidance was required to communicate the interplay between these two risks (e.g., https:/www.cdc.gov/coronavirus/ 2019-ncov/php/smoke-faq.html). Research and development of new technologies are 
needed to meet this complex and evolving challenge. This Research Topic brings together six publications providing important new data sets, end user tools, and insights into effective public health messaging and risk reduction actions.

\section{SMOKE AND PUBLIC HEALTH INFORMATION DATA AND TOOLS}

Assessing wildland fire smoke risk necessitates the fusing of information about smoke exposure and the affected population. To support a variety of potential smoke risk assessment investigations, Vargo combined the US Census Block Group Centers of Population with the National Oceanic and Atmospheric Administration (NOAA) Hazard Mapping System Smoke product covering a June 2010 through December 2019 time span. This resulting data set exceeding 59 million records can help accelerate research to understand smoke exposure in the United States and, in Vargo's words, “can be important for targeting funding, interventions, and communications to areas more often impacted by smoke from fires." In Australia and Canada, two innovative end user tools have been developed to support public health response by combining critical data sets to inform timely action by individuals and public health agencies. The Air Quality Visualization (AQVx) tool, described by Williamson and Lucani, is a smoke risk management tool that combines modeled and measured $\mathrm{PM}_{2.5}$ (mass of particles with aerodynamic diameter $<2.5 \mu \mathrm{m}$ ) concentrations, crowd-sourced smoke and symptom reports from the complementary AirRater smartphone application, fire information, population density, and locations of sensitive populations (aged care facilities, schools). A noted utility of AQVx is to support government messaging of risk to affected communities. The British Columbia Asthma Prediction System (BCAPS), described by Henderson et al. (https://maps.bccdc.ca/bcaps/), integrates smoke forecasts using an innovative methodology with health indicator data to predict the number of asthma inhaler dispensations over the coming days.

\section{COMMUNICATING STRATEGIES TO REDUCE SMOKE EXPOSURE}

Public health communication is most impactful if the delivery of information connects with the intended audience and

\section{REFERENCES}

1. Johnston FH, Henderson SB, Chen Y, Randerson JT, Marlier M, Defries RS, et al. Estimated global mortality attributable to smoke from landscape fires. Environ Health Perspect. (2012) 120:695-701. doi: 10.1289/ehp.1104422

2. Reid CE, Brauer M, Johnston FH, Jerrett M, Balmes JR, Elliott CT. Critical review of health impacts of wildfire smoke exposure. Environ Health Perspect. (2016) 124:1334-43. doi: 10.1289/ehp.1409277

3. DeFlorio-Barker S, Crooks J, Reyes J, Rappold AG. Cardiopulmonary effects of fine particulate matter exposure among older adults, during wildfire and non-wildfire periods, in the United States 2008-2010. Environ Health Perspect. (2019) 127:37006. doi: 10.1289/EHP3860 motivates exposure reduction action. Research in the midst of an emergency is challenging to accomplish but provides critical insights. Marfori et al. conducted a qualitative study in Tasmania, Australia, immediately after a prolonged and significant wildfire smoke episode to elucidate the complexity of smoke risk communication. Interviewees who lived near to the fires were faced with concurrent property and smoke risks, and recommended actions were sometimes in conflict (e.g., work outside to reduce fuels around your home for fire prevention; stay inside and rest to reduce smoke exposure). Other interviewees, at a lower risk from the fire, wondered why the risks from the significant smoke exposure were not well-communicated by emergency services nor consistently covered by the media. In another study, Hano et al. described quantitative insights gained through volunteer participants in the US Environmental Protection Agency (EPA) Smoke Sense smartphone application and research study (https://www.epa.gov/air-research/smoke-sensestudy-citizen-science-project-using-mobile-app). They found that the participants grouped by perspectives, not demographics, in terms of their responses to wildfire smoke risk.

To capture the current state of knowledge on risk reduction methods, Davison et al. hosted and summarized a web summit focused on the creation of cleaner indoor air spaces during smoke events. At the time this article was developed, it was noted that no national building guidelines existed. An important recent development was the release of the publicly available American Society of Heating, Refrigeration, and Airconditioning Engineers (ASHRAE) Planning Framework for Protecting Commercial Building Occupants from Smoke During Wildfire Events (17). This precedes the full Guideline 44 document, expected in 2022.

Significant wildfire smoke episodes affect many regions worldwide and this risk is anticipated to grow in the future (18). On an international scale, sharing new technologies, data sets, and insights will support more effective risk communication strategies to protect public health.

\section{AUTHOR CONTRIBUTIONS}

$\mathrm{GH}$ and WC wrote the first draft of the manuscript. All authors contributed to manuscript revision, read, and approved the submitted version.
4. Holm SM, Miller MD, Balmes JR. Health effects of wildfire smoke in children and public health tools: a narrative review. J Expo Sci Environ Epidemiol. (2021) 31:1-20. doi: 10.1038/s41370-020-00267-4

5. Dennekamp M, Straney LD, Erbas B, Abramson MJ, Keywood M, Smith K, et al. Forest fire smoke exposures and out-of-hospital cardiac arrests in melbourne, australia: a case-crossover study. Environ Health Perspect. (2015) 123:959-64. doi: 10.1289/ehp. 1408436

6. Wettstein ZS, Hoshiko S, Fahimi J, Harrison RJ, Cascio WE, Rappold AG. Cardiovascular and cerebrovascular emergency department visits associated with wildfire smoke exposure in California in 2015. J Am Heart Assoc. (2018) 7:e007492. doi: 10.1161/JAHA.117.007492 
7. Holstius DM, Reid CE, Jesdale BM, Morello-Frosch R. Birth weight following pregnancy during the 2003 Southern California wildfires. Environ Health Perspect. (2021) 120:1340-5. doi: 10.1289/ehp.11 04515

8. Amjad S, Chojecki D, Osornio-Vargas A, Ospina MB. Wildfire exposure during pregnancy and the risk of adverse birth outcomes: A systematic review. Environ Int. (2021) 156:106644. doi: 10.1016/j.envint.2021.106644

9. Fann N, Alman B, Broome RA, Morgan GG, Johnston FH, Pouliot $\mathrm{G}$, et al. The health impacts and economic value of wildland fire episodes in the U.S.: 2008-2012. Sci Total Environ. (2018) 610-1:8029. doi: 10.1016/j.scitotenv.2017.08.024

10. Matz CJ, Egyed M, Xi G, Racine J, Pavlovic R, Rittmaster R, et al. Health impact analysis of PM(2.5) from wildfire smoke in Canada (2013-2015, 2017-2018). Sci Total Environ. (2020) 725:138506. doi: 10.1016/j.scitotenv.2020.138506

11. Borchers-Arriagada N, Palmer AJ, Bowman DMJS, Williamson GJ, Johnston FH. Health impacts of ambient biomass smoke in Tasmania, Australia. Int J Environ Res Public Health. (2020) 17:3264. doi: 10.3390/ijerph17093264

12. Ford B, Val Martin M, Zelasky SE, Fischer EV, Anenberg SC, Heald $\mathrm{CL}$, et al. Future fire impacts on smoke concentrations, visibility, and health in the contiguous United States. GeoHealth. (2018) 2:22947. doi: 10.1029/2018GH000144

13. Abatzoglou JT, Williams AP. Climate change has added to western US forest fire. Proc Natl Accad Sci USA. (2016) 113:117705. doi: 10.1073/pnas.1607171113

14. International Union of Forest Research Organizations. 2018 Global Fire Challenges in a Warming World. Robinne FN, Burns J, Kant P, de Groot B, Flannigan MD, Kleine MM, et al., editors. Occasional Paper No. 32. Vienna: IUFRO (2018).

15. Henderson SB. The COVID-19 pandemic and wildfire smoke: potentially concomitant disasters. Am J Public Health. (2020) 110:1140-2. doi: 10.2105/AJPH.2020.305744

16. Zhou X, Josey K, Kamareddine L, Caine MC, Liu T, Mickley LJ, et al. Excess of COVID-19 cases and deaths due to fine particulate matter exposure during the 2020 wildfires in the United States. Sci Adv. (2021) 7. doi: 10.1126/sciadv.abi8789

17. ASHRAE. Planning Framework for Protecting Commerical Building Occupants From Smoke During Wildfire Events. (2021). Available online at: https://www. ashrae.org/file\%20library/technical\%20resources/covid-19/guidance-forcommercial-building-occupants-from-smoke-during-wildfire-events.pdf

18. Xu R, Yu P, Abramson MJ, Johnston FH, Samet JM, Bell ML, et al. Wildfires, global climate change, human health. N. Engl. J. Med. (2020) 383:217381. doi: 10.1056/NEJMsr2028985

Author Disclaimer: The summary thoughts presented here are those of the authors and should not be construed to represent any official U.S. Environmental Protection Agency, U.S. Department of Agriculture, or U.S. Government determination or policy.

Conflict of Interest: The authors declare that the research was conducted in the absence of any commercial or financial relationships that could be construed as a potential conflict of interest.

Publisher's Note: All claims expressed in this article are solely those of the authors and do not necessarily represent those of their affiliated organizations, or those of the publisher, the editors and the reviewers. Any product that may be evaluated in this article, or claim that may be made by its manufacturer, is not guaranteed or endorsed by the publisher.

Copyright (c) 2021 Hagler, Henderson, McCaffrey, Johnston, Stone, Rappold and Cascio. This is an open-access article distributed under the terms of the Creative Commons Attribution License (CC BY). The use, distribution or reproduction in other forums is permitted, provided the original author(s) and the copyright owner(s) are credited and that the original publication in this journal is cited, in accordance with accepted academic practice. No use, distribution or reproduction is permitted which does not comply with these terms. 